\title{
Medical Image of the Week: Acute Encephalopathy in a Multiple Myeloma Patient
}

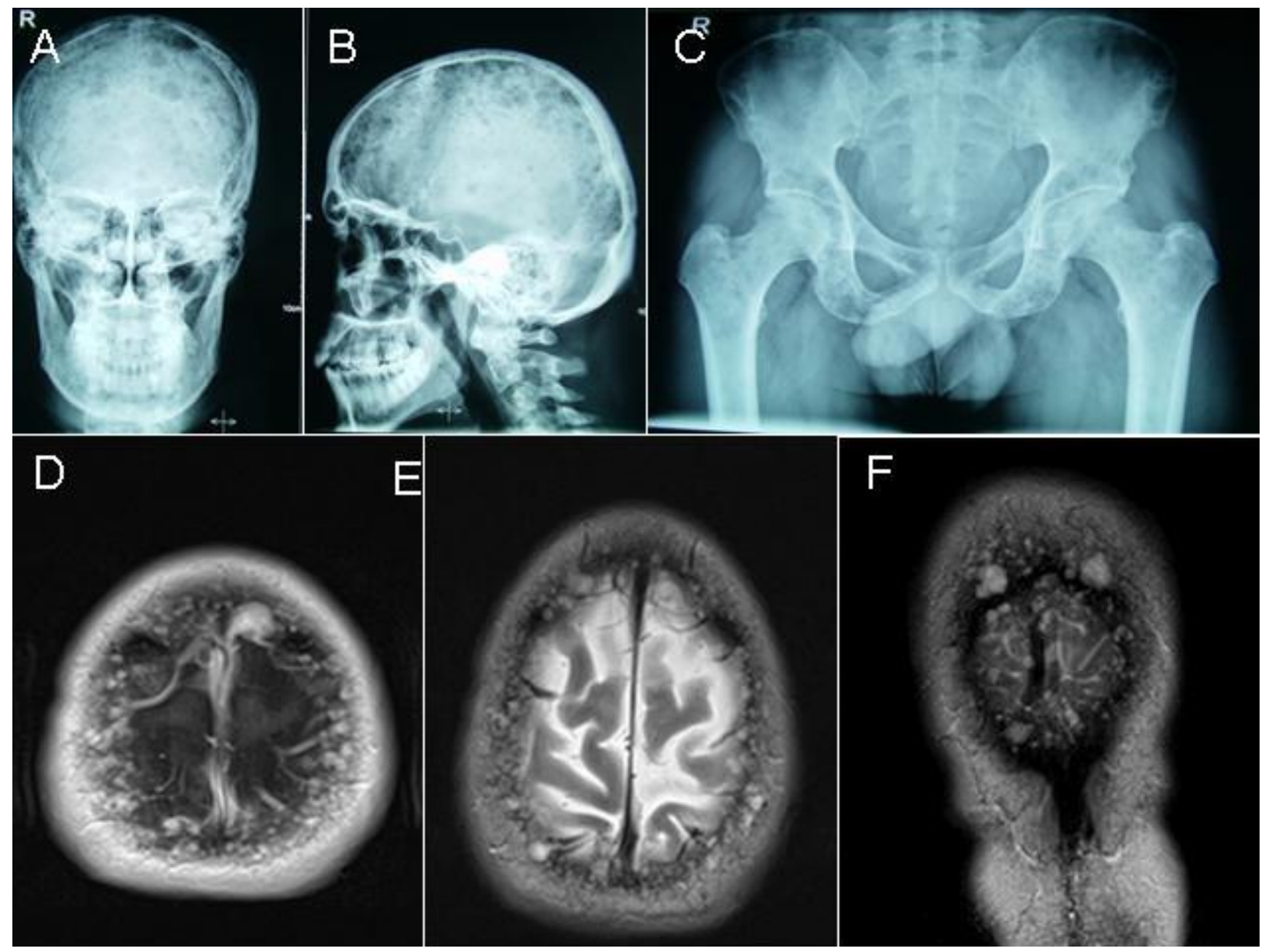

Figure 1. Panels A, B \& C: Skeletal survey with multiple well-defined "punched out" lytic lesions in the skull and pelvis bones. Panels D, E \& F: Magnetic resonance images show infiltration and replacement of bone marrow in the skull with highly vascular lesions due to tightly packed plasma cells.

A 45-year-old man with new diagnosis of multiple myeloma waiting to start treatment presented with worsening dizziness, blurred vision that progressed to altered mental status over a week. His physical exam revealed confusion but no focal deficit. His extensive work up showed no abnormality except for mildly elevated serum viscosity. The patient was started immediately on plasmapheresis. He also received dexamethasone, thalidomide and cyclophosphamide. His symptoms resolved completely within a few days of therapy.

Serum viscosity measurements do not correlate well with symptoms or the clinical findings of hypervicosity syndrome. Plasmapheresis promptly relieves the symptoms and should be performed in symptomatic patients regardless of the viscosity level $(1,2)$. 
Huthayfa Ateeli, MBBS and Laila Abu Zaid, MD

Department of Medicine

University of Arizona

Tucson, AZ USA

\section{References}

1. Gertz MA, Kyle RA. Hyperviscosity syndrome. J Intensive Care Med. 1995 MayJun;10(3):128-41. [CrossRef] [PubMed]

2. Palumbo A, Rajkumar SV, San Miguel JF, et al. International Myeloma Working Group consensus statement for the management, treatment, and supportive care of patients with myeloma not eligible for standard autologous stem-cell transplantation. J Clin Oncol. 2014 Feb 20;32(6):587-600. [CrossRef] [PubMed] 